Article

\title{
Design Engagements at the Margins of the Global South: De-Centering the "Expert" Within Me
}

\author{
Uttaran Dutta \\ Hugh Downs School of Human Communication, Arizona State University, Tempe, AZ 85281, USA; \\ uttaran.dutta@asu.edu
}

Received: 12 August 2019; Accepted: 11 October 2019; Published: 14 October 2019

\begin{abstract}
Conceiving everyone as a potential designer and believing in local peoples' informed understandings and agentic capabilities in addressing local problems, my design research journey was committed to opening up avenues for sustained transformations in the underserved spaces of rural eastern India. In my design engagements, we (community members and I) contributed in three design projects, namely design for community development (DfCD), information design for development (IDfD), and design for grassroots innovation (DfGD). In my design journey, I sincerely questioned/challenged my presumptions and design approaches as well as reflexively reoriented myself to make the design processes culturally meaningful and contextually appropriate. Being constantly cognizant about minute traces of superiority (and sense of indispensability) within me, being willing to challenge, modify, and rediscover myself continually, as well as privileging and situating local and indigenous perspectives and knowledge at the center of design processes, characterize some of the key learning of my design journey.
\end{abstract}

Keywords: reflexivity; culture; privilege; India

\section{Introduction}

Increasingly, academic discursive spaces are recognizing that the acts of designing are not necessarily confined to the contributions of designers; rather, non-designers can also demonstrate their potential to define and solve problems. As Manzini [1] argued, "we live in a society where everybody designs" (p. 40), the discipline is emphasizing and investing more and more in building capacity, reducing dependency and ensuring emancipatory transformations [2]. Importantly, scholars have noted that local and indigenous people have meaningful contextual knowledge and deep insights about their lived realities to potentially address issues of their own communities [3]. In making the world a better place (specifically sustainably transforming underserved spaces), academicians, practitioners and other stakeholders are diligently contributing to several missions and United Nation's sustainable development goals is one of the exemplars. (Specifically, in marginalized contexts of the global South, we, the design researchers, can potentially play important roles in accomplishing many of the goals-including Goals 1 and 2 (end poverty and hunger); Goals 3 and 4 (ensure good health, well-being and quality education); Goal 6 (ensure clean water and sanitation, and affordable and clean energy); as well as Goals 5 and 10 (achieve gender equality and reduce inequality), among others [4]). From the perspective of design studies, Van de Poel [5] argued that to attain the goal of social sustainability, it is important to prioritize and pay attention to the needs of the world's poor and/or marginalized populations. Design scholars have also emphasized several humane and socio-cultural concerns in the context of social sustainability, including equitable distribution of resources, fulfillment of basic needs, quality of life issues, community participation (incl. trust-building), and preservation of cultural resources [6]. In documenting the sustainable development goals, the United Nation refers to culture for the first time in their agenda of international development [7]. 
Furthermore, scholars have argued that the issues of underserved contexts of the global South are often multifaceted and intricate, which are difficult (if not impossible) to address effectively using predetermined and linear approaches, and essentially requires socially responsible and contextually appropriate designer attention [8]. de Sousa Santos [9] defined the global South not as a geographical concept, but rather conceptualized as a metaphor for marginalization (including delegitimization of human voices and agencies) perpetuated globally by dominant power structures, and as a marker of initiatives and resistance to addressing and overcoming such conditions. Thus, the epistemologies of the global South, by embracing de-colonial and de-Westernization (and beyond West-centric) lens, argue in favor of plurality, diversity and ecology of knowledge. Kang [8] has further opined that externally dictated and top-down design interventions often fall short in the global South contexts as the dominant approaches often fail to fully grasp the situated dynamics and complexities of socio-political scenarios; therefore, the effectiveness and impact of such interventions are limited from a sustainability point of view.

Cipolla \& Bartholo [2] have noted that design studies scholars have expressed a growing interest in addressing issues of social transformation and equality. Furthermore, McMahon \& Bhamra [10] have shown that the shifting paradigms of design are aligning increasingly with user-led (instead of material-led), and seeking to address wider social-/human-needs. In making design more humane, sustainable and socially embedded, inclusion of marginalized voices and agencies, methodological flexibility, reflexive design thinking (e.g., "what you do, how we do it, and why we do what we do" [11]), and attitude of learning from the below are crucial [12]. In other words, we need to be mindfully proactive and socio-culturally engage to bring about sustained transformation in the society [13]. Moreover, it is crucial for us to be able and willing to see our own unearned privilege, taken-for-granted assumptions, unexamined preconceptions that are deeply grounded in our embodied colonial and capitalist legacies [14]. Thus, in the journey of introspection, we (designers) need to be sincerely cognizant about our roles, positions, actions, and approaches [15]. In addition, scholars have noted that considering local people not as mere receivers or users of design outcomes, we need to conceptualize them as active co-designers and co-creators; in other words, a blurred boundary between the community members and us (designers) is potentially instrumental in making design contextually appropriate and sustainable [16].

In the journey of reflexive co-creation, scholars have cautioned us about the rise of "expertocracy", which often embrace unilinear approaches and thus make design engagements less inclusive [17]. Cross [18] noted that oftentimes expert designers pay inadequate time and attention to define design issues and analyze problems, as well as exhibit reluctance to abandon their preferred solution concepts. Scholars have questioned and challenged such approaches as experts try to fit pre-defined models (sometime unintendedly) and because privilege of the experts are often unquestionably celebrated [19]. Instead, design thinkers call for responsive and meaningful engagement with local (so-called lay or tacit) knowledge and practice, which would potentially open the way for culturally appropriate co-creation and unobtrusive dialogue between designers and non-designers [20,21]. Guided by such calls, this article on one hand seeks to challenge the notion of uncritical expertise and praxis based on unreflexive assumptions, and on the other hand intends to contribute to the debate on questioning less mindful design expertise in marginalized contexts.

In my research journey, I had the opportunity to work with several underserved communities of eastern India working towards attaining some of the aforementioned goals. More specifically, I participated in three design projects in the rural and indigenous spaces, namely design for community development (DfCD), information design for development (IDfD), and design for grassroots innovation (DfGD). In my design journey, I intended to question/challenge my presumptions and design approaches as well as reflexively reorient myself to make the design processes more culturally meaningful and contextually appropriate. Intercultural competence, solidarity, reflexivity and willingness to (un)learn are some of the important aspects to situate community members at the center of the design processes as well as decenter the expert within me to make design initiatives humane, inclusive, and sustainable. 


\section{Literature Review}

To make the design journey sustainable and inclusive, McMahon \& Bhamra [10] have opined that the following aspects potentially guide our design thinking: "history, traditions, dialogue, equity in expressing ideas, cultural diversity, ethics, collective and personal responsibility, satisfying physical and social needs, compromise, accountability, self-fulfillment and altruism" (p. 367). However, scholars have expressed concerns that that the "social" aspects oftentimes remain de-legitimized in sustainability discourses and called for placing social and cultural aspects at the center of future sustainability discussions [22]. Scholars have argued that the social aspects of sustainability are usually difficult to define as well as hard to implement [23]; moreover, the social aspect has yet to receive serious attention from researchers (particularly in comparison to environmental and economic aspects of sustainability. Furthermore, scholars have noted that broader dimensions and concerns of social, cultural, political and ideological aspects of social sustainability are not adequately understood in the wider discipline of design studies [24]. Again, from disciplinary perspectives, Asheim, Kjøllesdal and Boks [25] have noted that although some designers are working on socio-cultural aspect of sustainability, we need to engage and explore more both theoretically as well as methodologically.

Such people- and context-centered design strategies fundamentally focus on re-localization and decentralization to legitimize place-based knowledge (and ways of knowing), local voices and agencies, build possibilities of community-led transformative interventions [26]. Scholars have further argued that understanding local perspectives and priorities, recognizing and adopting local values and wisdom, meaningfully communicating with local people is not only instrumental in generating empirical design knowledge, but also essential for making design interventions humane and sustainable [8]. In this regard, design researchers are required to pay increased attention to day-to-day contexts, environment, relationships and situated practices and dynamics of local communities to co-create possibilities of social transformations [27].

In other words, scholars have questioned and criticized uncritical design expertise and de-contextual design emerging "from nowhere", and argued in favor of "local accountability", where designers and researchers pay attention to situated socio-politics, ideologies, and epistemologies in locating, positioning and situating design solutions [27]. Scholars have conceptualized the notion of expertise as a marker of delegated authority that privileges specialized knowledge, which oftentimes presume that people experience difficulties to successfully manage or achieve their goals independently (i.e., without assistance) $[28,29]$. Challenging expertise-centric approaches, specifically in the global South contexts, scholars have called for addressing the conditions of marginalization by embracing reflexive, organic, and engaging methods without essentializing pre-framed and predominantly intuitive approaches [18]. Such critical design engagements never try to undermine the values and importance of existing design pedagogy and praxis, rather by centering the underserved, their voices and agencies, capabilities, ideas, and wisdom, seek to bridge the knowledge and praxis of designers and participants in every phase of design initiatives [29].

Moreover, it has been noted by scholars that despite having good intentions to decenter the hegemonic and unilateral practices, oftentimes many participatory initiatives are co-opted into mainstream discourse and incorporated into the dominant practice; which not only defeat the purpose and goals of participatory initiatives, but also unintentionally foreground dominant knowledge and expertise [30]. Kothari [31] argued that participation can potentially be seen as a new means of control, as design activities are contingent upon researchers' (good) intentions and mindsets; particularly when the ownership and decision-making processes often lie in the hand of researchers and funding institutions. Along with mindfully acknowledging the importance as well as the potential loopholes of participation, this article also prioritizes less (externally) dependent community mobilization, where cultural participants have more control and ownerships. von Unger [32] conceptualized such an approach as self-organization (i.e., extending beyond participation), where community members collectively lead interventions without solely depending on external assistance (including material and knowledge resources). 
Many critical and indigenous scholars challenge the mainstream representations and practices of knowledge production [14]. Historically, the entry and acceptance of local and indigenous voices and wisdom in the dominant discursive spaces have remained limited, conditional and contingent [14]. They essentially argue in favor of reflexive listening to alternate ways of knowing and thinking, as well as recognizing situated concerns, aspirations and perceptions of the others with respect and openness [14]; such a gesture according to them would open up possibilities of dialogue between indigenous science and sustainability science. Thus, listening to and learning from local, indigenous, and traditional knowledge and knowledge holders in developing new sustainability ethics and praxis, is one of the key steps to potentially facilitate long-term and meaningful interdisciplinary dialogue [33]. Moreover, Stegall [34] opined that transdisciplinary engagements, by acquiring and/or sharing adequate knowledge of various academic domains (including engineering, communication and human interactions), and integration of relevant experiences and intercultural competence, as well as mindful sensibilities and concerns about socio-political, environmental, and humanitarian issues are critical.

In essence, challenging most globalization narratives and intentions, scholars have emphasized local- and people-centric design approaches to ensure plurality of knowledge and diversity of thoughts and practices [26,35]. Reflecting on contemporary contexts, scholars have noted that a handful research initiatives have focused on design for social change; and they opined that more research is needed to understand the nuances, boundaries and implications of such design interventions focusing on marginalized spaces (on social change) [36]. Kang [8] showed that design for social change fundamentally challenges the West-centric knowledge production that not only is grounded in objectivity and denies "other" ways of knowing, but also, is invested in binary thinking (i.e., West vs. rest, developed vs. underdeveloped) and builds boundaries between rational and socially creative ways of knowledge production (to de-legitimize other ways of knowing). To conduct contextually meaningful design research, Tuck \& Yang [37] have noted that we need to de-Westernize our mind, actions, and approaches, so that we can learn to value local knowledge, ethics, ideologies, perceptions, and arguments, and thereby potentially dismantle and challenge our deeply embodied colonial ways of knowing and thinking.

Manzini [38] has argued that we need to design with community (i.e., not design for community), where we would participate as peers with diverse stakeholders, facilitate dialogue, share ideas, and promote collaboration towards co-creating shared visions, co-constructing solutions, and co-developing communities, i.e., instead of subscribing to our (designers') own wants and preferences, such an approach essentially emphasizes local knowledge and aspirations, cultural diversity, social equality, and justice, human rights, and focuses on participation, communication, as well as identity and freedom of the local communities [2,15,39]. However, in contexts of the global South, scholars have also mentioned that cultural and contextual barriers (including linguistic and communicative challenges) pose significant challenges to the designers in their attempts to build meaningful solutions and community's capacity in a sustained manner $[8,40]$. Therefore, our ability to listen to and engage with culturally diverse narratives, not only facilitate empathic dialogue and foreground the unheard voices, but also orient the design processes towards plurality and ecology of knowledge [41,42]. Thus, co-developing and exploration of avenues with diverse stakeholders as well as creation of spaces for mutual learning from underserved voices and practices are instrumental (i) to understand the situated realities and the nuances experientially and (ii) to sustainably address the situated needs, aspirations and goals at the margins $[8,12,43]$.

\section{Contexts and Methods}

Many underserved communities of the global South including rural indigenous people of eastern India and their voices and agencies are not well represented in discursive spaces of design studies. Geographical remoteness, lack of connectivity and contact are some of the potential reasons for such discursive silence. Apart from physical remoteness, cultural and communicative barriers pose 
challenges in conducting research with underserved communities. These barriers included my own ethnocentrism and taken-for-granted assumptions, barriers to earning trust, language and literacy barriers, habitual muteness and cautious skepticism of communities, and lack of access to technological (including Internet) and material resources.

Moreover, my socio-political identities and unearned privileges (i.e., non-indigenous middle-class urban Indian male, educated in a Western university, embodies legitimacy as an "expert"), I was largely perceived as an outsider in these underserved spaces. Historically, my ingrained identities and privileges symbolize prolonged abuses and exploitations of marginalized populations of rural South Asia. As a researcher, I have been working with rural eastern Indian communities since 2008 and spent several months (primarily in summer) there every year. In facilitating design research as well as documenting and learning from the communities' roles in solving their problem, my role was of a participant observer. In doing so, I participated in research conversations (including focus groups and in-depth interviews) and recorded my observations, reflections, and learning experiences. The contexts of three projects/domains of study are presented below:

(i) Design for community development (DfCD) projects: These design research projects were conducted with rural and indigenous communities with weak domestic and/or communal economy, who were experiencing a lack of access to resources and services. As an outcome of the research, we (community members and I) co-developed local infrastructures and co-created communicative and cultural solutions to address situated issues in three remote and marginalized regions—forest, coastal, and Himalayan regions. More specifically, we constructed a mini-hospital and an indigenous library-cum-museum as well as co-organized theater-like performances in local indigenous languages to create awareness and legitimize local voices. We organically (i.e., in non-predetermined ways) identified situated design problems and potential solutions based on long-term engagements and deliberations.

(ii) Information design for development (IDfD) projects: Digital divide as well as information and communication shortages have become increasingly visible in many underserved of rural eastern India. In these projects, bottom-up and culturally appropriate IDfD solutions were co-designed, including both mobile apps and computer applications, to foster local development as well as to bridge the digital divide. One of the computer applications, Unnayan, sought to co-create access to information and feedback mechanism as well as to aid the collective content generation to reduce existing information gaps and help marginalized stakeholders in taking context-specific decisions in real time from their local spaces in local language. Another initiative, an Android-based mobile application, Sangraksha, was designed to facilitate attempts of the writing history from below, and to preserve rare cultural artifacts, which are practiced and/or produced in remote underserved spaces.

(iii) Design for grassroots innovation (DfGI) initiative: This exploratory initiative sought to motivate and engage local youths from marginalized sections of the community (specifically is scheduled caste and scheduled tribe communities) to become innovators, so that they would creatively solve local issues using local resources. After attending workshops and participating in a 6-week long design process (i.e., starting from problem identification to development of solution or prototype), the local youth addressed many of the problems they experienced in their everyday lives.

As previously mentioned, the goal of this paper is to reflexively question and examine the notions (and traces) of expertise in my research journey in marginalized contexts of the global South. In the next section, after discussing the situated barriers and contextual challenges, I focus on three aspects of this journey: (i) how community feedback and interactions guided the process of problem identification, (ii) how the effective intervention avenues were co-defined and co-developed, and (iii) how the design interventions were led and the knowledge produced from the below. Grounded in my own experiential journey, the realizations and illustrations are presented espousing the lens of subjectivity and introspection. In a way, this was a journey of mindfulness towards achieving 
reflexivity. When connecting the dots in retrospect, I realized that my design engagements at the margins were essentially an attempt to decenter the expert deep-seated within me.

\section{Results}

This section describes my learning, negotiations, and reflections in the field while experiencing contextual barriers and attempting to build trust and collegial relationships, co-defining and co-developing solutions, and exploring new avenues/approaches.

\subsection{Addressing the Contextual Barriers}

While conducting field work, I have noticed and experienced several contextual barriers which posed challenges to design research, described below. Such barriers were cultural and communicative in nature, including.

Literacy barriers: recent data shows that illiteracy among four rural indigenous populations in eastern India is very high and among women illiteracy is even higher [44]. Moreover, there are a significant number of school dropouts in these communities [44]. Therefore, to me, sticking to text-only options could be an inflexible design decision in the research context (even if a text-option was convenient for develop). As the cultural participants experienced difficulties to read, with consultation of community members, I used visual and sensory (primarily audio and tactile) elements to make the design processes inclusive and accessible by the villagers (please refer to an example mentioned later).

Language barriers: Many rural and indigenous people, oftentimes owing to the geographical remoteness, were denied the opportunity to learn and communicate in dominant languages. Such a scenario essentially created communication gaps between underserved communities and the mainstream population. While they conversed in indigenous languages within their communities, rural indigenous people communicated in dialects of mainstream languages (e.g., Hindi and Bengali) to converse with outsiders (like me). These local dialects (of mainstream languages) oftentimes embody indigenous vocabularies. For example, the Simantararhi and Jharkhandi Bengali is a dialect of Bengali language spoken in the southwestern part of Bengal, which contains several Santali (and local indigenous languages') words. Thus, use of formal Indic language while facilitating design interactions was not only inappropriate, but also could make the research process a distant and disconnected one. Therefore, I learnt the dialect as well as frequently used local indigenous words in the course of my field research to bridge the communication gap.

Skepticism: Owing to past experiences of living under colonial rule (which was often oppressive and abusive, and lasted over more than two centuries), the rural indigenous populations were very skeptical about the intentions of dominant stakeholders and discourses. Scholars have noted that in such a scenario, cultural participants exhibit deference effects (for example, they strategically choose words and expressions to please the interviewers), and oftentimes get accustomed to muteness owing to prolonged oppression. This communicative challenge requires a responsive and flexible research approach to address such contextual realities. In my fieldwork, I experienced both types of behavior; moreover, I noticed that the participants were not comfortable talking to me in one-on-one situations, rather they preferred group conversations. For them, one-on-one conversations might create confusions and controversies among the villagers about the content and the intention of the interaction. To make my research culturally appropriate, rigorous, and acceptable, I interacted with the community members multiple times and often in the group situations.

Social cultural barriers (particularly caste barriers): Discriminations and prejudices against lower caste (and indigenous people) are still a reality in remote and rural India (and in many parts of South Asia); and, such exclusionary practices are widely visible in many underserved spaces. Therefore, as a researcher I needed to be socially accepted so that my presence could become non-threatening to the community. While initially skeptical about my research and intentions, after multiple meetings and spending time, over the years, indigenous people gave me the opportunity to research with them. To make sure about my cultural orientation, local communities oftentimes invited me to share food in 
public setting (sharing food is often seen by them as breaking the barriers of untouchability) as well as invited me to stay with them in their homes; that was a rare privilege for me to spend time with cultural participants. Moreover, while staying with them, I participated and helped them in their day-to-day activities, which greatly enriched my understanding of their lived realities and contextual nuances.

\section{2. (Re) Learning New Ways of Knowing}

Smith [45] showed that the West had historically rejected alternate ways of knowing and denied local people's rights to be owner of knowledge production; moreover, she called for reclaiming knowledge and human rights by challenging (but not rejecting) the hegemonic ways of knowing. Scholars, those who are studying underserved population (including indigenous people) of the global South, question taken-for-granted assumptions and "scientific" rationality that dictates the discursive spaces of decision-making. Therefore, while theorizing about incompatibilities and communicative impossibilities between local/indigenous and mainstream ways of knowing, these scholars called for engaged dialogue between sustainable science and indigenous science. For example, most of the indigenous communities of eastern India practice animism (believing in the presence of life in inanimate objects and oftentimes worshipping them); I noticed, before initiating any work or making significant community decisions, they seek permission from and/or worship sacred trees (which they considered to be their gods). Moreover, much of the local/indigenous decision-making was guided by their spiritual (and supernatural) consciousness, which to some of my colleagues (scholars as well as practitioners) were mere superstition and not "scientific". Before conducting research, I had a preliminary (mainly bookish, and that too with a trace of ethnocentrism) knowledge about animism, but my understating was inadequate to fully capture the essence of animism; however, through regular interactions I gradually learnt the nuances of their worldviews and practices. When the communities are historically accustomed to muteness, my "rational" rejection (or any hint of rejection) of their so-called "pseudoscientific" discourses would not only make them more voiceless, but would also act as a conversation stopper. Preparing me to be able to listen to cultural voices with compassion and openness as well as communicate with openness were important lessons of my research journey. Again, intercultural competence and empathy were essential to interact and learn the intricacies of the lived realities. In reality, it was not easy, at least initially, for me to understand how they prioritize collective needs (i.e., by going above and beyond individual preferences and benefits) and their non-profit oriented and/or non-material outlooks; reflexive engagement over the years aided me in overcoming my incompetence.

\subsection{Trust-Building Aspects}

My perception about field studies (its intensity, time commitment) and what it takes, was initially shaped by my own experiences (mostly from academic spaces) and learning from the journey of seniors and scholars. Many a time, field research is a matter short-term engagement or a couple of interactions with cultural participants. In my journey, i.e., researching with rural indigenous populations, who constantly experienced several cultural and communicative barriers (mentioned above), demanded more intensive and immersive engagements. Moreover, my participants were neither my "clients" (as I was never invited or recruited by the communities), nor did they expect any specific material outcomes from me; rather my involvement was a spontaneous and humanitarian one (i.e., giving back to the society, especially to those who are living at the margin), which gradually emerged out of my conscience and commitment. Consequently, oftentimes, my research, presence and the overall intention yielded some skepticism (initially, in most of the cases) to community members. In other words, it was needed to overcome my embodied unearned privileges to overcome situated trust-building barriers. Therefore, it takes immersive engagements and multiple interactions for several weeks (even months) and that too for several years to gain their confidence and trust. In other words, the process of understanding the dynamics of researcher-community relationships was a new learning experience for me, which eventually reoriented myself towards building my competence. For instance, in most of the villages, 
my first-year interactions were more formal. From second year onwards, as some community members were able to recognize me, they started taking me seriously. Largely, from the third year on, I was able to talk to them about possible design interventions and community participation. Having said that, I must admit that my interactions with rural indigenous people were heavily influenced by "summer" biases (i.e., short-term stays from mid-May to mid-August), i.e., even with multiple visits over several years, my knowledge about underserved communities and their practices were in a sense incomplete; therefore, my research is always dependent on and appreciative of local ways of knowing and on the situated wisdom.

\subsection{Defining Problem and Identifying Solution(s)}

While building trust is foundational to community interaction, initiating design research warrants specific focus on and familiarity with socio-cultural and communicative aspects. Particularly when cultural participants were experiencing linguistic barriers and exhibited deference effects, socio-political marginalization posed additional challenges. Oftentimes, verbal-only conversations would fall short and fail to fully capture and represent the complexities of indigenous realities and practices. In response, with help and guidance from local communities, I gradually co-created an interviewing approach-ILGI (Iconic Legisigns Guided Interviewing) (details of the approach are discussed elsewhere) to meaningfully interact with the communities. By ensuring inclusivity, flexibility, access, and discursive control of participants over interview processes, ILGI approach sought to give "some degree of power back to the subjects" (p. 92) [46]. In the process, I used handmade cards with line-drawn images (guided and approved by as well as meaningful to local communities) to initiate conversations and conduct interviews (Figure 1). The visuals not only guided interaction processes, but also helped to communicate (as well as register) the discussion topics to less literate participants better; moreover, combinations of cards/topics yielded more specific and nuanced discussion about situated issues. In addition, involvement of community members in handling and debriefing the topics/cards helped the community to own and control (to a large extent) the interaction process. In addition, the approach helped the research process in observing evaluating and prioritizing local issues and thereby facilitating the design decision-making process. Inclusive engagements of the community members (i.e., in multiple sessions) enriched the interaction process and helped to define design problems in a collective and informed way.

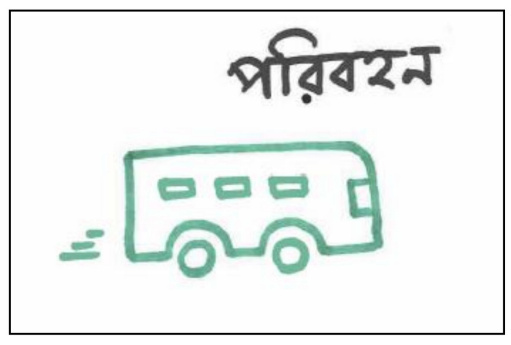

(a)

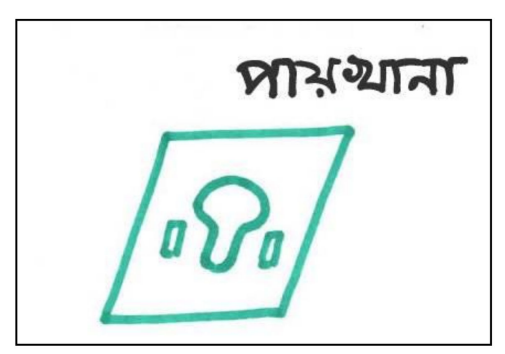

(b)

Figure 1. Images of cards used in Iconic Legisigns Guided Interviewing. (a) Transportation; (b) Sanitation.

Regular interactions with the community members and their informed inputs, not only prevented the process from considering predetermined solutions, but also made the process community-driven and organic. Multiple interactions paved the way for engaged deliberations as well as opened up avenues for examining and weighing options together. In other words, communicative engagements in listening to and dialoguing with the cultural participants essentially legitimized voices at the margins as well as influenced the discursive decision-making spaces. 


\subsection{Constant Feedback at Each Step}

Scholars have argued that community members are often knowledgeable about the surrounding contexts and can be considered to be a useful resource in addressing situated problems. However, in many information design research (particularly those which are conducted at the margins), involvement of cultural participants is often less than adequate. Guided by the principles of participatory and co-designing practices, I learnt to involve and include local people in every phase of designing activities. For instance, initially, while designing user interfaces for computer applications I used images that were available on Internet by editing them. Community members, after reviewing those images, advised me not to use those images and to produce culturally appropriate visuals. Accordingly, I requested the villagers to participate in a community drawing session, where community members participated in drawing, sorting and choosing visual representations of local issues and/or phenomena. Later, the chosen images were redrawn using photo editing software and included in the user interface (Figure 2). Starting from visualizing the interfaces, the community members participated in every phase of decision-making (e.g., deciding the content, navigation system, graphic elements, and so on). As we co-developed multiple versions of the interface with numerous modifications in each version, showing the participants the final interface (of each version) would make the research process less rigorous and engaged. Moreover, deference effects and muteness were other communicative challenges (as previously mentioned), which could potentially bring my ideas and assumptions to the center of design process. Therefore, it was necessary to seek constant feedback from the community and iterate the interface design accordingly. Interacting with participants on a regular basis (almost every day), villagers saw the entire design process as a collective, and shared their evaluation and feedback on a constant basis. For example, when one of the images developed based on community inputs was shown the community, they immediately detected some of the wrong depictions and guided me to modify the images:

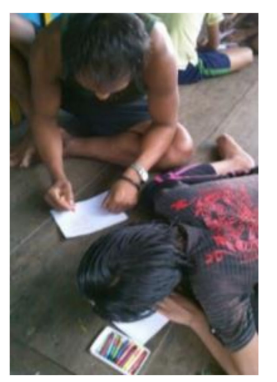

(a)

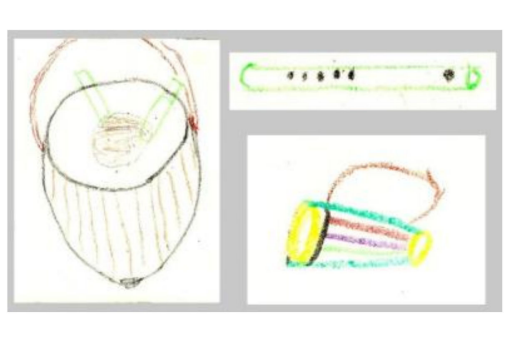

(b)

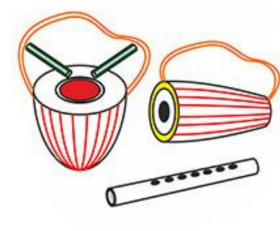

(c)

Figure 2. (a) Community drawing session; (b) Image of "culture" drawn by the villagers; (c) Image redrawn using computer.

I: Tell me more about the color of "Madoli" (a musical instrument)

Haru: The color should be red, instead of this central area; use yellow here.

I: Ok, the same will be applied to the other side, right?

Haru: Our "Madoli" has two sides, one side is black and one side is colored.

Along with minute modifications as above, the community also took strategic decisions. For example, rooted in the conversations with cultural participants, we co-created a password system that used only visuals. While evaluating the first prototype (Figure 3), a community member commented: 


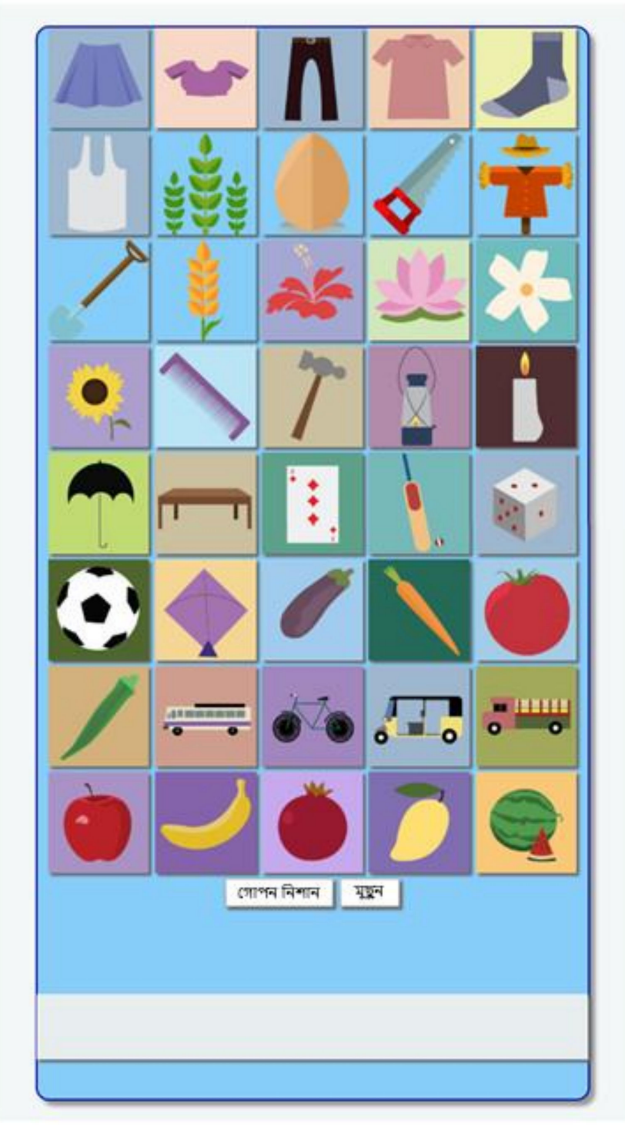

Figure 3. Of password screen.

I: Are you facing any difficulty understanding this?

Barin: It is very much understandable from the pictures. The moment you see them you can figure it out. I have a suggestion: please improve the image of the scarecrow and the shovel.

I: Sure, I will do that. Let me ask, in the case that illiterate participants are using these pictures to create a password, will they be able to remember their password or not?

Barin: Definitely, they will be able to.

Thus, feedback and thought from within the communities guided the design process as well as shaped the outcome.

\subsection{Community Members as Co-Designers, Facilitators, and Teachers}

During my design interactions, I gradually realized that the design processes needed more inclusive involvement from the community members. Taking communities' inputs and developing solutions by taking their feedback, to me, was not making the community members co-designers and/or co-researchers. Moreover, while conducting interviews (and research in general), I experientially realized my limitations to fully capture, read, and comprehend community thoughts and feedback, especially because of linguistic barriers and communicative nuances (i.e., untold and told (but not literal) and between the lines feedback). Therefore, I requested three community members to join designing process on a full-time basis (and I paid compensation for their contributions); i.e., throughout the day they spent time with me, watched every minute step, shared their suggestions in real time. Such involvement from the community helped me to learn socio-cultural dynamics of underserved communities in new lights as well as guided me to grasp new meanings and significance of their everyday practices. For example, after joining as full-time members of the design team, in a few 
days they gradually participated as facilitators in community interaction sessions. As interview facilitators when they posed questions, the inquiry became more community-driven and socially embedded, and therefore more authentic and yielded thicker descriptions. Again, they also assumed the roles of teachers in describing and teaching interface navigations to fellow villagers. Moreover, when other community members informally interacted with them, they received additional feedback. Upon sharing, this additional feedback became a crucial component for improving and refining the designing process.

\subsection{Designing In Situ}

In contrast to designing for community development or for grassroots innovation that usually takes place in local spaces, the information design activities (particularly user interface designing) are done in research labs/studios. Even if developing interface in studio/laboratory was a convenient option, my research sites and settings, being remote, posed different challenges and warranted appropriate measures. Some of them were technological—for example, availability of electricity was intermittent and sometimes not available for a couple of days; network-related-telecommunication signal was very weak/unavailable in certain areas; also availability of Internet was unpredictable; computational skill-related-most of the community members had limited or no experience of using computing devices; moreover, inability to read English posed an additional challenge to other computing abilities, and socio-cultural-appropriate knowledge was needed to make interfaces culturally respectful, and easily understandable/recognizable by the less literate community members. Therefore, designing interface in offsite studios and then coming back to rural spaces for collecting feedback, to me, potentially made desired outcomes less contextual and sustainable especially when anticipating and addressing emergent complexities and developments were crucial [47]. For example, determination of sizes of images and audio clips, so that they could be easily downloaded in actual scenarios, was done based on the actual lived experiences. Similarly, the semantic effectiveness of the images, messages, integrations, and overall design was thoroughly co-developed with the guidance and assistance of the community members. For instance, broadcasting of an Internet-based local radio channel (a feature of one computer application) was tested in the villages with active participation of the villagers.

\subsection{Using Locally Available Materials, Resources, and Skills}

To make the design sustainable in the long run, especially when the underserved community did not have enough money to buy or spend on things independently, choice of materials was crucial. One of the design-driven community development projects—a mini-hospital—was conducted in remote Himalayan villages to co-create access to health. In discussions about hospital accessories, local health professionals suggested buying standard hospital beds made of iron, and I initially could not see any problem with that proposal. Later, the villagers pointed out that owing to high altitude and geographical isolation (i.e., no proper road was there to connect the villagers, therefore working on foot was the option), it was very difficult (if not impossible) to manually carry hospital beds, which are made with iron, is a high attitude region. Moreover, in the long run when the iron beds might be damaged or rusted (especially in these high rainfall regions), they would need to be repaired. When these issues were brought forward, villagers collectively decided to choose wood as an alternate material, particularly when the wood (coming from legal sources-i.e., from trees that have fallen down or died) was abundant in that forest area. Later, they built a few other things such as saline stands (maintaining the actual measurements) using wood as well. Villagers argued that as and when required they could easily repair these hospital accessories, as we had the adequate skill of the resources available locally. Similarly, villagers also built hand tools from household items that were used in the project, one of them was a paint brush, which was made from a shoeshine brush. 


\subsection{Participation and Beyond Design Led by Local Communities}

In participatory and co-designing processes, participants usually respond to the call of designers. In other words, ownership of the design process still lies with the designers in conventional participatory research praxis. As previously mentioned, my research program explored both participation and self-organization (i.e., beyond participation [32]) options. In at least two projects, I have seen that, given an opportunity, community members can own and effectively lead the research independently. To me, such community engagement could be an ideal precondition to make a design outcome sustainable. In the design for community development projects, such as building a hospital and a library-cum-museum, the villagers gradually took ownership of the whole process in terms of decision-making and implementing ideas. For example, in the last phase of a library-cum-museum project, villagers decided to use murals to decorate the space. Accordingly, they used three strategies to collect examples from nearby spaces: they started looking at the available indigenous books and resources to collect design examples, they asked me to collect photographs from nearby villages where good murals are available on the walls, and they also communicated with local indigenous artists conversant with the art form. Based on their collected information, they collectively discussed several options in terms of choosing designs, and feasibility of implementing the chosen designs based on their available time and skill sets. Apart from the mural implementations, in another project, villagers took ownership to design messages of social awareness through theater-like performances. In that project, two villagers who had past experiences of writing stories, wrote an initial script and directed others to perform. Every night they performed in front of a few enthusiastic and experienced community members. Based on consistent feedback from the community every evening, the initial script was gradually modified. The final outcome of the theater-like performance was therefore socio-culturally impactful and effective.

\subsection{Design Influenced by Local Examples}

Oftentimes, emerging situation requires learning from local examples. In one design for community development (DfCD) project the villagers decided to work toward creating access to better health by creating a health infrastructure. However, we (community members and I) did not have any first-hand experience of building such facility. Even if I gathered some information from secondary texts (including existing case studies and online audio-visual contents), they were not helpful in addressing health access issues in remote mountainous village. Such a scenario essentially necessitates experiential co-learning from examples existed in the nearby places. Accordingly, we visited several health facilities and hospitals, and learnt about their operations as well as the resource requirements. Based on the observation and discussion with doctors and administrators, we came up with plans and suggestions, which eventually helped us to design the health facility. Similarly, in other projects such as library-cum-museum, and grassroots innovation projects, learning from local wisdom, knowledge, and examples were integral component of designing solutions. Such an attempt to learn from local stakeholders made the design interventions inclusive, where everyone could contribute and be responsible for transforming local spaces. Therefore, seeking help from neighbors, well-wishers and local scholars would potentially play a role in making the design experience interdisciplinary and an effort to bridge contextual barriers.

\subsection{Grassroots Innovations}

When underserved people across the global South are constantly negotiating to access structural and communicative resources, academics and practitioners are increasingly paying attention to exploring creative agencies in the marginalized spaces. In a DfGI initiative, a research on grassroots innovation (6 weeks long research during the summer each year) was conducted in underserved regions of rural eastern India. Marginalized lower-caste youths (age 14-25, both male and female) participated in the research to build solutions and products to address and improve local scenarios 
towards achieving self-sufficiency and imagining a more sustainable future. In the design research initiative, my role was to take a backseat, and situate the community members at the center of problem-solving activities as innovators and leaders. At the beginning, a two-day workshop was conducted, where we (participants and I) studied the basics of design by collectively exploring forms and innovative usages of locally available materials. The participants were given six weeks to identify local problem (based on lived experiences) and produce a solution or prototype. Their final outcome was later examined and evaluated by the senior members of communities to assess suitability and effectiveness. For example, in one project—community garbage bin—the participants, two high-school students, built a garbage-bin prototype suitable for $4-8$ neighboring families. Upon everyday use of the garbage bin, the bin would yield large amount of compost at the end of season/year. Apart from making the environment cleaner the garbage bin could also light a small bulb for domestic usage at evening time (Figure 4). In another project, a student of class nine built a portable shed for privacy during defecation. Open defecation, which spreads disease, is a matter of serious concern, as it is still in practice in many parts of southwestern Bengal. This temporary measure to protect privacy as well as to spread awareness messages, a portable shed was designed with locally available used gunnysacks that displayed graphics and catchy phrases to communicate messages. Example such as these potentially demonstrated the designer potentials and agentic capability of local youths to solve their local problems independently (if they are given the opportunity to foreground their voices and thoughts).

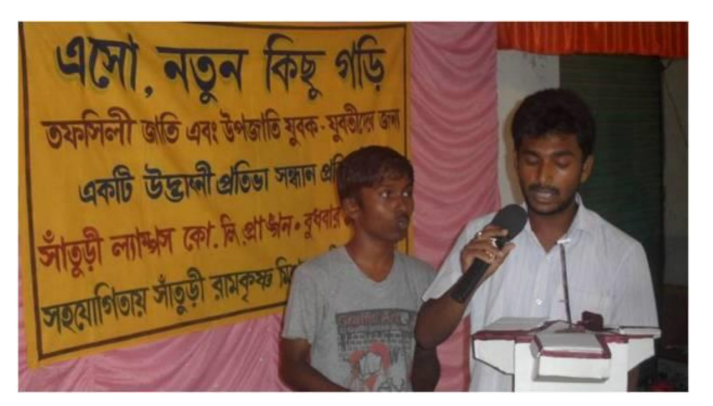

Figure 4. Participants displaying a prototype of the garbage bin.

\subsection{Learning from Below}

Inverting the roles of knowledge producers (in the conventional sense) is an important consideration to make design sustainable. Smith [46] showed how on one hand indigenous people are denied their ownership is knowledge producers; and on the other hand, they are treated as mere receiver of dominant knowledge. Instead of uncritically subscribing to dominant/established perspectives, the local participants can be envisioned as frontrunners and teachers, who can teach/lead design activities in a dialogic and organic manner. In one incident, I designed the initial interface of one computer application for the community based on my book knowledge and preconceptions-i.e., circular elements are "appropriate" for indigenous context. When the villagers saw the design, they found it inadequate and not so interesting. During community discussion, senior women, who were master craftsmen in the village invited me to join a session, where they offered to teach me the basics of local indigenous aesthetics and design sensibilities (Figure 5). In that session, they brought several natural resources such as leaves, woods and stones, and created several things, using those resources in front of me. Many such examples of design patterns and aesthetics, which they presented to me, were eye-opening and transformed my understanding of indigenous design preferences, expectations, and aspirations. 


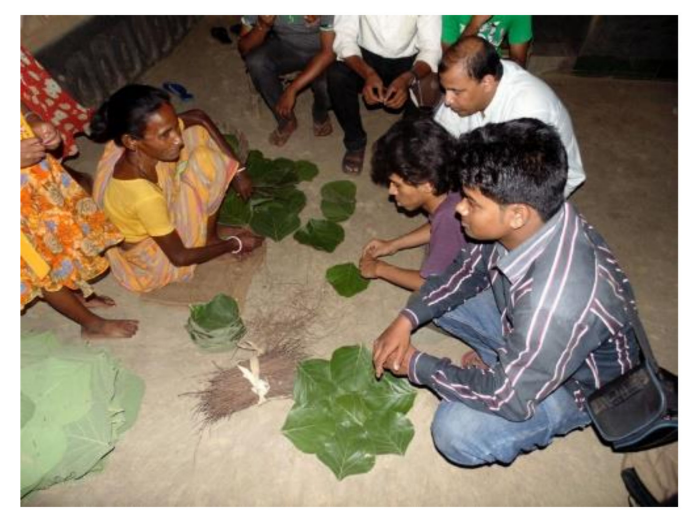

Figure 5. Design workshop conducted by the community members.

In addition, I invited regular feedback from them about overall research approach (es) and processes (i.e., not just about the specific design project) to facilitate the process of constant examination of me and my work through the eyes of the participants. To me, if the design solution (and embedded design philosophy) was not meaningful or acceptable to the local community, most likely the outcome would be unsustainable. Therefore, paying attention to spirituality, aspirations, and expectations of the local community were a precondition for me in making any design sustainable.

\section{Discussion}

Reflexive and engaged design involvements towards ensuring adequate and sustained access to resources and services at the margins in an inclusive and socially embedded way, is a need for the hour, particularly when the global South, including rural India, is experiencing severe structural, discursive, and power disparities. Design for sustainable social change, according to scholars, needs to pay diligent attention to address contextual issues and disparities experienced by these underserved populations [36]. Such design engagements, by paying attention to social, political, moral and ecological dimensions, envision a just society that promotes cultural diversity and plurality, create equal opportunity as well as fight against all kinds of disparities [36]. In global South contexts, many designers oftentimes not only take their privileges for granted in an unreflexive way [48], but also their expertise oftentimes lacks contextual knowledge (including historical, social and cultural understanding), and primarily emphasize technical knowledge. Future of design could imagine and potentially ensure engaged interaction between designers and non-designers as well as between universal and local epistemologies to integrate technical knowledge with cultural nuances, situated values and aspirations [29].

Thus, effective design initiatives for sustainable social change is essentially contingent on our understanding of human behavior, values, and contextual realities, as well as our commitment to meaningfully address human needs and expectations. Guided by our mindfulness, competence, sensibilities, and preparedness as well as by agentic capabilities, values, practices, and situated knowledge of cultural participants, such design engagements would potentially co-create avenues for meaningful change, empowerment, and equality. Some of the key components of such an approach are defining the design problem(s) and identifying the solution avenues together with local people; transdisciplinary knowledge production through collaborations and conversations; and empowering and enhancing local capacities by reducing existing dependencies [1,49]. While the aforementioned principles and aspects guided and shaped my research journey, my design engagements at the margins emanated three thoughts and/or reflections, which I elaborate on in the following paragraphs.

\subsection{Re-Calibrating and Re-Forming Myself}

As a design researcher it is crucial for me to unlearn and introspectively de-construct my embodied ethnocentrism, unearned privileges as well as unexamined presumptions and practices that potentially 
cause formidable barriers to learning and innovating. Such engagements helped me in exploring new learning and relearning endeavors that potentially opened up socio-culturally meaningful knowledge production and problem-solving avenues. In other words, challenging my unearned privileges, ethnocentric assumptions, and sub-/un-conscious senses of superiority as well as self-introspecting to act mindfully, compassionately, and ethically was pivotal to my design journey. Apart from unlearning and relearning, reflexive communicative engagements (including critical listening and mindful dialogue) and intercultural competence was essential to re-build and prepare myself. Scholars have noted that critical listening engagements essentially question societal power dynamics and uncritical assumptions that foreclose local voices; whereas a dialogic involvement fundamentally opens up avenues for co-constructing respectful and impactful interactive environment in bringing about transformations [50,51]. Such engagements were crucial for me to potentially bridge situated interactive barriers, silences and even the communicative impossibilities that divide the societies, and to make design research open, inclusive, and conducive. Moreover, in less-known cultural contexts, inculcating and nurturing the qualities of intercultural competence such as empathy and compassion are crucial for me in making design engagements conducive, respectful, and emancipatory.

\subsection{Beyond Participation-Self-Organization}

As opposed to modernist and top-down approaches to design, scholars have argued in favor of participatory and co-creative involvements, where the designers and community members work hand in hand as co-researchers $[52,53]$ to potentially reduce dependency on external resources and expertise, and to build avenues for empowerment and change [54]. Questioning the West-centric and hegemonic approaches, critical scholars envision cultural participants as the central organizing force and active guiding entity for community mobilization [55]. Furthermore, scholars have called for critically examining and de-centering the exogenous experts and knowledge production practices to bring about sustainable transformations at the margins of the global South. In my design engagements, legitimizing situated social and cultural resources as valuable entities, and prioritizing local autonomy were important for me towards co-creating affordable, customized and sustainable designs [56]. In my design journey, I sought to legitimize meaningful community mobilization and agentic control over the process, encouraging cultural participants to take over and independently organize design initiatives. Scholars term such approaches as self-organization (i.e., extending beyond participation; e.g., von Unger, [32], where participants collectively assume the leadership/ownership by minimizing or eliminating dependence on external resources and knowledge.

\subsection{Left the Place as if I Was Not Here Before}

The quotation is taken from (Late) Prof R. K. Joshi's (a founding member and former head of Industrial Design Center, Indian Institute of Technology—Bombay) keynote lecture in 2007 ICOGRADA (International Council of Communication Design) Design Week, Mumbai. I embraced the wisdom embedded in the expression as one of the key guiding principle in my research. In some sense, the phrase celebrates the essence of grace (i.e., not forcing, dictating or intruding into spaces) and demonstrates gratitude while conducting design research by embodying the principles of feminism and humanitarianism. The act of "invisibilizing" the designer (but not the contributions), essentially pave the way for centering the participants and their efforts in bringing about sustainable change. Embracing the principle, I considered myself as valuable and indispensable as any other community member, and believed that my contributions would only be valued and remembered if they made any differences in the lives of people. In other words, being constantly cognizant about minute traces of superiority (and sense of indispensability) within me, being willing to challenge, modify, and rediscover myself continually as well as privileging and situating local and indigenous perspectives and knowledge at the center of design processes, characterize some of the key learning of my design journey.

Sharing the experiential learning with future researchers can potentially create possibilities of scholarly discussions, and in essence provide more examples to future researchers. Instead of 
embodying and subscribing to a pre-defined (and often solely intuitive) model, future designers need to be more socially, culturally and geographical informed [31]. Furthermore, by espousing organic and contingent character and being open to critical discussion, design activities can potentially become socio-culturally meaningful, accountable, transparent and inclusive $[19,57]$. Reflexively engagement with (including listening to and dialogue with) cultural participants would potentially enrich and inform contemporary design thinking and practices through learning from participants' perspectives, aesthetics, and experiential knowledge [19]. In other words, such involvements of participants in design activities would not only methodologically advance the discipline but enhance its relevance and values [19]. While the domain of design is going to play a game-changing role in this century [58,59], we need to be cognizant about epistemological determinisms and inflexibilities, uncritical ethnocentrism and cultural illiteracies that are embedded in hegemonic praxis. It is, therefore, important for the design scholarship to recognize and understand and bridge the axiological and praxiological gaps towards crating epistemic plurality and ecology of transformation (avenues to counteract damages of global capitalism towards building sustainable communities) [26,35].

This article represents experiences, learning, and projects of a single researcher; the discussion can be expanded in the future by involving other researchers and their engaged learning. Inclusion of different experiences, perceptions and thoughts on various design initiatives (i.e., geographically, demographically, topically and methodologically diverse research projects) would open up new discursive possibilities and richer multiprong discussions.

Funding: This research received no external funding.

Conflicts of Interest: The author declares no conflict of interest.

\section{References}

1. Manzini, E. Collaborative Organisations and Enabling Solutions: Social Innovation and Design for Sustainability. In Collaborative Services. Social Innovation and Design for Sustainability; Jegou, F., Manzini, E., Eds.; Edizioni Polidesign: Milan, Italy, 2008; pp. 29-41.

2. Cipolla, C.; Bartholo, R.A. Dialogical Approach to Socially Responsible Design. Int. J. Des. 2014, 8, 14.

3. Palaganas, E.C.; Sanchez, M.C.; Molintas, M.; Visitacion, P.; Caricativo, R.D. Reflexivity in qualitative research: A journey of learning. Qual. Rep. 2017, 22, 426-438.

4. United Nations. Sustainable Development Goals. 2015. Available online: https://sustainabledevelopment.un. org/?menu=1300 (accessed on 30 July 2019).

5. Van de Poel, I. Design for sustainability. Philos. Technol. Environ. 2017, 2, 121.

6. Lilley, D. Design for sustainable behaviour: Strategies and perceptions. Des. Stud. 2009, 30, 704-720. [CrossRef]

7. UNESCO. Culture: At the heart of SDGs. 2017. Available online: https://en.unesco.org/courier/2017-apriljune/culture-heart-sdgs (accessed on 30 July 2019).

8. Kang, L. The Case of a Handcraft Pottery Community in Cambodia. Int. J. Des. 2016, 10, 65-74.

9. De Sousa Santos, B. Epistemologies of the South: Justice against Epistemicide; Routledge: New York, NY, USA, 2015.

10. McMahon, M.; Bhamra, T. 'Design Beyond Borders': International collaborative projects as a mechanism to integrate social sustainability into student design practice. J. Clean. Prod. 2012, 23, 86-95. [CrossRef]

11. Storer, I.; Badni, K.; Bhamra, T.; Farmer, S. Communicating sustainable design. Des. Technol. Educ. Int. J. 2008, 10, 44-57.

12. Smith, R.C.; Iversen, O.S. Participatory design for sustainable social change. Des. Stud. 2018, 59, 9-36. [CrossRef]

13. Manzini, E. Context-based wellbeing and the concept of regenerative solution. A conceptual framework for scenario building and sustainable solutions development. J. Sustain. Prod. Des. 2002, 2, 141-148. [CrossRef]

14. Johnson, J.T.; Howitt, R.; Cajete, G.; Berkes, F.; Louis, R.P.; Kliskey, A. Weaving Indigenous and sustainability sciences to diversify our methods. Sustain. Sci. 2016, 11, 1-11. [CrossRef]

15. Manzini, E. New design knowledge. Des. Stud. 2009, 30, 4-12. [CrossRef] 
16. Luck, R. Dialogue in participatory design. Des. Stud. 2003, 4, 523-535. [CrossRef]

17. Brand, R. Synchronizing Science and Technology with Human Behavior; Earthscan: London, UK, 2005.

18. Cross, N. Expertise in design: An overview. Des. Stud. 2004, 25, 427-441. [CrossRef]

19. Brand, R.; Karvonen, A. The ecosystem of expertise: Complementary knowledges for sustainable development. Sustain. Sci. Pract. Policy 2007, 3, 21-31. [CrossRef]

20. Lane, M.B.; McDonald, G. Community-based environmental planning: Operational dilemmas, planning principles and possible remedies. J. Environ. Plan. Manag. 2005, 48, 709-731. [CrossRef]

21. Collins, H.M.; Evans, R. The third wave of science studies: Studies of expertise and experience. Soc. Stud. Sci. 2002, 32, 235-296. [CrossRef]

22. Boyer, R.H.W.; Peterson, N.D.; Arora, P.; Caldwell, K. Five Approaches to Social Sustainability and an Integrated Way Forward. Sustainability 2016, 8, 878. [CrossRef]

23. Clark, G.; Kosoris, J.; Hong, L.N.; Crul, M. Design for Sustainability: Current Trends in Sustainable Product Design and Development. Sustainability 2009, 1, 409-424. [CrossRef]

24. Melles, G.; Kuys, B.; Kapoor, A.; Rajanayagam, J.; Thomas, J.; Mahalingam, A. Designing technology, services and systems for social impact in the developing world: Strong sustainability required. In ICoRD'15-Research into Design Across Boundaries Volume 2; Chakrabarty, A., Ed.; Springer: New Delhi, India, 2015; pp. 89-98.

25. Asheim, J.; Kjøllesdal, A.; Boks, C. Coming of Age as Design (Er) for Social Sustainability. In Proceedings of the 14th International Conference on Engineering \& Product Design Education (E\&PDE12) Design Education for Future Wellbeing, Antwerp, Belguim, 6-7 September 2012; pp. 525-530.

26. Escobar, A. Sustainability: Design for the pluriverse. Development 2011, 54, 137-140. [CrossRef]

27. Bjögvinsson, E.; Ehn, P.; Hillgren, P.-A. Design Things and Design Thinking: Contemporary Participatory Design Challenges. Des. Issues 2012, 28, 101-116. [CrossRef]

28. Turner, S. What is the problem with experts? Soc. Stud. Sci. 2001, 31, 123-149. [CrossRef]

29. Bäckstrand, K. Scientisation vs. civic expertise in environmental governance: Eco-feminist, eco-modern and post-modern responses. Environ. Polit. 2004, 13, 695-714.

30. Cooke, B.; Kothari, U. Participation: The New Tyranny? Zed Books: New York, NY, USA, 2001.

31. Kothari, U. Authority and expertise: The professionalisation of international development and the ordering of dissent. Antipode 2005, 37, 425-446. [CrossRef]

32. Von Unger, H. Participatory health research with immigrant communities in Germany. Int. J. Action Res. 2012, 8, 266-287.

33. Berkes, F. Sacred Ecology; Routledge: New York, NY, USA, 2012.

34. Stegall, N. Designing for sustainability: A philosophy for ecologically intentional design. Des. Issues 2006, 22, 56-63. [CrossRef]

35. Hathaway, M.; Boff, L. The Tao of Liberation: Exploring the Ecology of Transformation; Orbis Books: New York, NY, USA, 2009.

36. Vezzoli, C.; Ceschin, F.; Osanjo, L.; M'Rithaa, M.K.; Moalosi, R.; Nakazibwe, V.; Diehl, J.C. Distributed/Decentralised Renewable Energy Systems. In Designing Sustainable Energy for All; Springer: Cham, Switzerland, 2018; pp. 23-39.

37. Tuck, E.; Yang, K.W. Decolonization is not a metaphor. Decolonization Indig. Educ. Soc. 2012, 1, 1-40.

38. Manzini, E. Making Things Happen: Social Innovation and Design. Des. Issues 2014, 30, 57-66. [CrossRef]

39. Vezzoli, C. Design for Sustainability: The New Research Frontiers. In Proceedings of the 7th Brazilian Conference on Design, Curitiba, Brazil, 9-11 August 2006; pp. 83-106.

40. Dutta, U. Negotiating structural absences: Voices of indigenous subalterns of eastern India. J. Intercult. Commun. Res. 2018, 47, 52-71. [CrossRef]

41. Chiu, M.-L. An organizational view of design communication in design collaboration. Des. Stud. 2002, 23, 187-210. [CrossRef]

42. Fadeeva, Z. Promises of sustainability collaboration-Potential fulfilled? J. Clean. Prod. 2004, 13, $165-174$. [CrossRef]

43. Escobar, A. Notes on the Ontology of Design. 2012. Available online: http://sawyerseminar.ucdavis.edu/files/ 2012/12/ESCOBAR_Notes-on-the-Ontology-of-Design-Parts-I-II-_-III.pdf (accessed on 30 July 2019).

44. World Bank. West Bengal Social Inclusion. 2017. Available online: http://documents.worldbank.org/curated/ en/382741504252542549/pdf/119345-BRI-P157572-West-Bengal-Social.pdf (accessed on 30 July 2019).

45. Smith, L.T. Decolonizing Methodologies: Research and Indigenous Peoples; Zed Books: New York, NY, USA, 2013. 
46. Markwell, K.W. Photo-documentation and analyses as research strategies in human geography. Aust. Geogr. Stud. 2000, 38, 91-98. [CrossRef]

47. Dutta, U. Designing for the underserved: My reflections. DESIGNFORALL 2016, 11, 13-20.

48. Pease, B. Undoing Privilege: Unearned Advantage in a Divided World; Zed Books: New York, USA, 2013.

49. Papanek, V.J. Design for the Real World: Human Ecology and Social Change; Academy Chicago; Pantheon Books: New York, NY, USA, 1985.

50. Ganesh, S.; Zoller, H.M. Dialogue, activism, and democratic social change. Commun. Theory 2012, $22,66-91$. [CrossRef]

51. Sorrells, K. Intercultural Communication: Globalization and Social Justice: Globalization and Social Justice; Sage: Thousand Oaks, CA, USA, 2015.

52. Kapuire, G.K.; Winschiers-Theophilus, H.; Chivuno-Kurio, S.; Bidwell, N.J.; Blake, E. Revolution in ICT, the Last Hope for African Rural Communities' Technology Appropriation. 2010. Available online: https://researchspace.csir.co.za/dspace/bitstream/handle/10204/4587/Bidwell_2010.pdf?sequence=1 (accessed on 30 July 2019).

53. Nieusma, D. Alternative design scholarship: Working toward appropriate design. Des. Issues 2004, 20, 13-24. [CrossRef]

54. Braund, P.; Schwittay, A. The missing piece: Human-driven design and research in ICT and development. In Proceedings of the 2006 International Conference on Information and Communication Technologies and Development, Berkeley, CA, USA, 25-26 May 2006.

55. Chaturvedi, V. A critical theory of subalternity: Rethinking class in Indian historiography. Left Hist. 2007, 12, 9-28. [CrossRef]

56. Galdeano-Gómez, E.; Aznar-Sánchez, J.A.; Pérez-Mesa, J.C. The complexity of theories on rural development in Europe: An analysis of the paradigmatic case of Almería (South-East Spain). Sociol. Rural. 2011, 51, 54-78. [CrossRef]

57. Nowotny, H. The place of people in our knowledge: Towards local objectivity and socially robust knowledge. Eur. Rev. 1999, 7, 247-262. [CrossRef]

58. Dunne, D.; Martin, R. Design thinking and how it will change management education: An interview and discussion. Acad. Manag. Learn. Educ. 2006, 5, 512-523. [CrossRef]

59. Razzouk, R.; Shute, V. What is design thinking and why is it important? Rev. Educ. Res. 2012, 82, 330-348. [CrossRef] 